\title{
Crisis Governance, Emergency Management, and the Digital Revolution
}

Patrick S. Roberts

Shalini Misra

Joanne Tang

\section{Summary}

Digital technologies have fundamentally altered emergency and crisis management work through increased potential for role ambiguity, role conflict, distraction, and overload. $\quad \mathrm{M}$ ulti-level approaches to improve congruence between crisis managers and their environments have the potential to reduce cognitive and organizational barriers and improve decision-making. The future of crisis management lies in reducing the misalignment between personal, proximal, and distal environmental conditions.

\section{Keywords}

Information overload, digital technology, thinking, decision-making, emergency management, disaster governance, crisis organizations

\section{Digital Technology and the Future of Work}

Digital technologies have changed the nature of emergency and crisis management work by providing the manager more information at a faster pace and from many more communication channels. Increasingly, emergency managers must process large volumes of online and offline information and communication from partners and contacts spanning government, private, and non-profit sectors as well as ordinary citizens (Sagun, Bouchlaghem, and Anumba, 2009; Collins, Flanagan, and Ezell, 2015; Bennett 2014; Wukich and Mergel, 2015; Plotnick and Hiltz, 
2016; Hughes and Palen, 2012; Wukich, 2016; Stern, 2017). Disaster preparedness plans now include "digital readiness," which refer to the skills for using digital technology and the systems for verification and security of data (Smith, 2019). Even local governments have begun to use drones for image capture and for search and rescue operations. Smart devices and the Internet of Things provide real time information about unfolding crises. For example, the Lower Colorado River Authority in Texas, like many other jurisdictions, uses sensors to provide warnings about rising floodwaters (Kanowtiz, 2017).

New digital technology provides opportunities for collaboration, learning, and decision-making, but these are layered on top of existing routines that vary by country (Bryer \& Zavattaro, 2011; Janssen, Chun, \& Gil-Garcia, 2009). For example, in the United States county-level emergency managers may be located in their own department, or inside a police or sheriff's office. Some emergency management routines reflect the profession's historical and organizational proximity to policing, fire, and civil defense by, for example, using the concepts of vulnerability and preparedness (Collier and Lakoff 2008, 2015).

In China, emergency management offices often mirror "all hazards, all phases, all stakeholders" principles of the national level disaster agency (Lu and Han 2019). The phrase refers to a disaster agency's responsibility to prepare for many kinds of events affecting many kinds of people. In principle, technologies in China will have to adapt to be similarly open-ended to match the seemingly limitless range of hazards for which they will have to prepare. Many other countries operate according to similar models (Natural Hazards Governance in Australia; Natural Hazards Governance in India).

Over time, $\mathrm{n}$ ew digital tools may contribute to refashioning old organizational routines by linking organizations across traditional boundaries. McCormick $(2016,207)$ finds that 
"emergency management tools are in a state of transition—-from formal, internally regulated tools for crisis response to an incorporation of new social media and crowdsourcing tools."

At the same time, the public has access to many more sources of information and communication channels. From the public's perspective, new digital technologies can provide new ways of organizing to manage crisis response. In the aftermath of Hurricane Harvey along the Texas Gulf Coast, private fishing and recreational boat operators formed the volunteer and ad hoc "cajun navy," to rescue people stranded in floodwaters (Smith et al. 2018; Stone et al. 2019). The group organized through text messages and social media. At the same time, new avenues for communication among the public provide havens for rumor (Xiao, Huang, and Wu 2015). Twitter and Facebook posts and Instagram images as well as direct text messages can take on a life of their own around dubious facts and images that may gain wide currency before crisis managers can counter them. Most research to date focuses on domains other than crisis management, but this research raises intriguing questions relevant to crises: How and why do rumors spread during crises (DiFonzo 2013)? Can crowdsourced information correct digital rumor (Starbird et al. 2014)? A case study of an online rumor about oil tank explosions in Japan shows that a correction from city hall in Urayasu diffused rapidly and the rumor became less prevalent (Takayasu et al. 2015). Does the same process hold in other disasters? Digital rumor and misinformation are now part of the background of crisis management work (Information and Communication Technology in Crisis and Disaster Management).

This essay considers how digital technologies have transformed emergency and crisis managerial work. It focuses on the pervasive and synergistic macro-environmental changes generated by digital technologies and their implications for the structure and functioning of emergency management work (Stokols, Misra, Hipp, \& Runnerstrom, 2008). It then outlines 
the implications of these macro-environmental and organizational transformations on managerial thinking and decision-making. The misalignment between humans and their environment, including technology, can exacerbate stressful conditions and make it more difficult for emergency managers to make decisions. The essay concludes by proposing multi-level approaches to improve congruence between crisis managers and their environments to reduce cognitive biases and improve decision-making. Despite the potential for misalignment, digital tools and organizational remedies may help managers cope with digital overload.

\section{The Ecology of Emergency and Crisis Management in the Digital Era}

\section{Macro-environmental Implications}

Crisis management involves understanding the situation, making sure critical decisions are made by the right people, and communicating with stakeholders and the public when the crisis ends (Boin, Stern, and Sundelius 2016, 4). Crisis managers may work in formal positions, or they may emerge ad hoc. Emergency management is one form of crisis management with its own history (Roberts $2013,70-112$ ). It emerged in the late $20^{\text {th }}$ century drawing on tools from civil defense, public safety, public administration, and planning. $\quad$ In the $21^{\text {st }}$ century, many countries have emergency management offices at different levels of government. In the United States, the national level agency, the Federal Emergency Management Agency (FEMA), has between 11,000 and 14,000 employees. State and local offices are much smaller, and countylevel agencies can have staff ranging from dozens in the largest counties to a single part-time emergency manager in the least populated ones. At all levels, the emergency manager is a coordinator of public, non-profit, and private efforts to prepare for and respond to a range of hazards and disasters. 
Emergency management work, like many other $21^{\text {st }}$ century work environments, has become a 24/7 job and extends beyond the confines of the office (Ingraham, 2009; Peters, 1992; Torres and Acerete, 2005). The 'beyond-the-office' environment requires managing continuous streams of information in computers, telephones, smartphones, printouts, and television and radio media (Sagun, Bouchlaghem, \& Anumba, 2009). Managers are not merely passive receptors or even surfers sitting atop the wave-they shape the information environment. Managers sometimes make targeted efforts to dispel rumors through social media posts, andœ many emergency and crisis managers maintain social media accounts for monitoring and communication. FEMA now lists social media as an element of emergency preparedness. In one recent study, county level emergency managers said that the public held unrealistic expectations that if there were an emergency communication such as a weather warning or evacuation order, it would "pop up on their Facebook feed or appear on their smartphone" (Misra, Roberts, \& Rhodes, 2020). Almost all managers in the study mentioned the increased pressure to respond quickly. Sutton, Palen, and Shklovski (2008) show that people turn to rumor when official channels are too slow to provide information.

The increasing proliferation of communication channels alters the power balance between the manager and the lay public - whereas before the advent and pervasive use of digital technologies the public was more likely to receive communications in a "one-to-many" fashion, now there is the possibility of "many-to-one" communication from public groups to crisis managers via text, email, and social media. The shifting power dynamics have implications for technology. M ost $21^{\text {st }}$ century emergency alert services are opt in - meaning that recipients must choose to receive the alert. However, some experts advocate for greater use of opt out 
technologies so that the government and emergency managers retain the power to include all residents in alert messages as a default (Moore 2010).

\section{Organizational Implications}

The changing macro-environment has important organizational implications for emergency and crisis management functions. The intensification of communication interchanges and the shifting power dynamics between emergency managers and the public in the digital environment result in role ambiguity and role conflict (Misra, Roberts, \& Rhodes, 2020). Role ambiguity occurs when a job's demands are ill defined, and role conflict occurs when a job places incompatible demands on a person, pulling them in different directions (Jung, 2013; Reid at al., 2008). For example, e mergency managers interviewed for a recent study reported that they had difficulty coping with the intensification of digital communication in the new work environment, including a challenge of setting boundaries between work and home (Misra, Roberts, \& Rhodes 2020).

$\mathrm{R}$ ole conflict and role ambiguity also occurs when managers are hired into organizations structured for a less public facing and more hierarchical environment, but have to contend with more frequent exchanges of digital information with the public and other government agencies. Additional examples of role ambiguity and conflict include challenges in mastering rapidly changing digital technologies that are often not designed for emergency management work and processing the onslaught of digital information and communication during emergencies (Misra, Roberts, \& Rhodes, 2020). In 2020, a consulting firm recommended that the County of Santa Barbara, CA move its Office of Emergency Management out of the county executive office and into the fire department. The consulting firm said the emergency 
management office "lacks the capacity and capability for ongoing communications and community engagement before and after incidents" including the 2017-18 Thomas Fire and deadly debris flows (Hayden, 2020). The six-person office was seen as too small to manage the pace and volume of communication required of managers in crisis situations.

\section{Cognitive, Affective and Behavioral Implications of Digital Ecologies in Emergency and Crisis Management}

The behavioral patterns and societal norms promoted by networked digital technologies like smartphones and handheld devices pose challenges for mental functioning. One premise is that the pervasiveness of networked technologies in every aspect of life poses significant impediments for information processing and the capacity for certain types of thinking among emergency managers (Misra, Roberts, \& Rhodes, 2020; Misra, Roberts, \& Rhodes, 2018). Challenges documented in the literature include the cognitive impairments from digital distractions, multitasking, digital overload, decreasing time and motivation for thoughtful reflection, and detrimental declines in memory, comprehension, learning, and the ability to evaluate the authority of information (Cain \& Mitroff, 2011; Lin, 2009; Ophir, Nass, Wagner, \& Posner, 2009; Pea et al., 2012). At the same time, the ability to synthesize and creatively integrate knowledge from different knowledge systems and evaluate the authority and credibility of information is a key skill for crisis and emergency managers in the $21^{\text {st }}$ century and beyond (National Academy of Sciences, 2012; Weber \& Khademian, 2008). Below we provide a summary of the research on the consequences of digital overload, distraction, and multitasking on higher order cognitive processes as they apply to emergency and crisis management. By definition, crisis managers must act quickly under situations that at once provide too little 
(imperfect) information and too much (irrelevant or incorrect) information. These managers are at the forefront of what it means to act and manage in the new digital environment.

\section{Impacts of Digital Overload, Distractions, and Multitasking on Thinking and Decision- making}

During emergencies, managerial decision-making is dependent on access to abundant and accurate information. Paradoxically, having too much information may lead to cognitive overload and inertia during a time when speed is critical to implement life-saving actions. In addition to receiving too much information, emergency and crisis managers may lack the tools to filter and process the information into manageable or easily understood packets, they may lack the ability to focus on the information, and they may lack confidence that the information is reliable (Peterson, 2017). After a 7.0 magnitude earthquake in Haiti in 2010, emergency managers faced information overload due to the increasing number of residents using mobile technology to request aid combined with the inadequate resources to filter and make use of the information that communities were providing. Responders felt overwhelmed and unable to critically read and assess information (Disaster Relief 2.0). Since the Haiti earthquake, cell phones have even become more common globally and are increasingly being used for everyday tasks such as banking and education. Emergency managers worldwide will need to address digital information processing and overload in order to respond effectively to crises (Bennett 2020).

A US-based survey of county-level emergency managers found that they spend 50 hours / week online and almost one-fifth of that time on email communication (Misra, Roberts, $\&$ Rhodes, 2018). Digital overload, or the feeling of being overwhelmed by digital-based 
demands that exceed one's perceived capacity for coping with the demands, (Misra \& Stokols, 2012) has negative consequences on workplace productivity, the ability to focus, decisionmaking, stress, employee morale, and health and wellbeing on a wide variety of sectors (Boswell, Olson-Buchanan, Butts, \& Becker, 2016; Butts, Becker \& Boswell, 2015; Mark, Voida and Cardello, 2012; Edmunds \& Morris, 2000; Eppler \& Mengis, 2004; Farhoomand \& Drury, 2002; Hwang \& Lin, 1999; Speier, Valacich, \& Vessey, 1999; LexisNexis, 2010). Emergency managers in the US who report high levels of digital overload also experience more stress, which is in turn linked to the tendency to not like to think too much or too deeply (analytical thinking). Not only that, digital overload was linked to the tendency to rely on intuitive thinking styles at a marginally significant level (Misra, Roberts, \& Rhodes, 2018). While more research with larger sample sizes is needed to strengthen these claims, the experience of chronic overload from digital sources imposes burdens on emergency managers' attentive capacities and depletes the available cognitive resources for more effortful and deliberative thinking.

In experimental studies focused on short-term outcomes, high levels of multitasking level result in poorer attentive capacity (Wilmer, Sherman, \& Chein, 2017) and lowered ability to distinguish relevant information from irrelevant information (Cain \& Mitroff, 2011; Lin, 2009; Ophir et al., 2009). Excessive multitasking leads to declines in information acquisition (Rockwell \& Singleton, 2007) and significantly weaker retention, learning, and comprehension of information (DeStefano \& LeFevre, 2007; Hembrooke \& Gay, 2003; Miall \& Dobson, 2001; Niederhauser, Reynolds, Salmen, \& Skolmoski, 2000; Poldrack \& Foerde, 2008). In addition to the cognitive impediments during short-term tasks, digital distractions can result in "resumption errors" - the tendency to commit errors in ongoing tasks after interruptions or switching tasks 
(Brumby, Cox, Back, \& Gould, 2013; Cades, Trafton, Boehm-Davis, \& Monk, 2007; Monk, 2004).

Comparable cognitive and behavioral impediments appear in field studies of organizational settings. Behavioral patterns promoted by digital technologies such as frequent task-switching, digital interruptions, and the attentional demands from multiple online and offline information streams result in lowered productivity, errors, and weakened memory and understanding (González \& Mark, 2004; Mark, González, \& Harris, 2005; Mark, Gudith, \& Klocke, 2008; Renaud, Ramsay, \& Hair, 2006; Leiva, Böhmer, Gehring, \& Krüger, 2012; Levy, Rafaeli, \& Ariel, 2016; Foerde, Knowlton, \& Poldrack, 2006; Greenfield, 2009). One study (KC, 2014) found that as Emergency Room doctors multitask more, they make fewer conclusive diagnoses resulting in more patients returning to the Emergency Room within 24 hours after discharge. During a shift, doctors treat multiple patients simultaneously and guide them through different phases, from initial evaluation of symptoms to testing, diagnosing, and decisions to admit or discharge the patient, while continually encountering new patients throughout their shift. During this period, the cognitive load of doctors varies and intensifies, as they may need to engage in swift task switching and pay attention to several inputs and sources of information at the same time. Doctors must remember details of the patient's history, reread test results, or do other recursive activity. They must also switch from patient to patient, repeating this behavior each time, all the while coordinating treatment and monitoring with other hospital staff members, further disrupting concentration and adding to cognitive overload (KC, 2014).

Networked technologies can interfere with focused attention even when users try to ignore them. A study by Stothart, Mitchum, and Yehert (2015) found that even when individuals do not attend to notifications and try to ignore them, the mere exposure to smartphone 
notifications has the potential to lead to poor performance on a concurrent task that requires focused attention, perhaps because they prompt task-irrelevant thoughts.

The evidence is more limited with respect to linkages between digital overload and distractions and longer term attentional and information processing capacities. A 2009 study by Ophir et al. found that chronic and excessive multi-taskers were also less able to filter environmental distractions and performed worse on a task-switching activity compared to individuals who did not multi-task as much over time. In effect, excessive multitasking inhibits individuals' ability to multitask effectively over time. Further, people who multitask heavily also tend to score high on attentional impulsivity (inability to focus attention or concentrate) measures and are more susceptible to task-irrelevant distractions compared to people who multitask less. In laboratory studies, chronic and heavy multitaskers performed poorly on working memory tasks even without distractions, had weaker information processing capacity and elevated scores on impulsivity and hyperactivity scales (Hadar, Eliraz, Lazarovits, Alyagon, \& Zangen, 2015; Uncapher, Thieu and Wagner, 2016; Frein, Jones, \& Gerow, 2013) indicating the possible negative longer term impacts of certain patterns and forms of digital technology use. In crisis management, some task switching may be inevitable given the influx of new information and new kinds of decisions. The best strategy would be to focus energy on the most important tasks and decisions. Decision aids, from continuity of operations and contingency plans, to response frameworks at the national level are intended to sort problems into decomposable decisions in sequence so that decision-makers can act deliberately without overload.

The combination of attentional impulsivity and poorer working memory have been found to lead to long-term memory impediments as well. Chronic media multitaskers are less able to 
draw on the past — recent or more remote - to inform their present behavior and they appear to have weaker executive functioning (Baumgartner \& Jones, 2015). Similarly, overreliance on digital technologies such as navigation systems have been found to impede spatial memory and cognition (Milner, 2016). Uncritical reliance on automated tools can result in cognitive biases and errors in decision-making, such as automation biases (Mosier \& Skitka, 1996; Parasuraman and Manzey, 2010). Less is known, however, about the long-term consequences of offloading certain types of higher order cognition onto digital technologies (Risko \& Gilbert, 2016). Csikszentmihalyi, Abuhamdeh and Nakamura (2014) found a negative relationship between smartphone usage and the capacity to achieve "flow" - "a state of concentration so focused that it amounts to absolute absorption in an activity". There is a growing body of research linking digital distractions and the overuse of these technologies to the reduction in the capacity to make empathetic and meaningful interpersonal connections (Gergen, 2010; Misra, Cheng, Genevie, \& Yuan, 2016; Turkle, 2012). The crisis management literature advises leaders to show empathy toward those affected by a crisis as a way of leading response and recovery (Wooten and James 364-365). If a leader lacks empathy, the leader risks falling short in a crisis. The leader of a small organization might never bother to manage by walking around and instead be glued to a computer. Or the manager might simply be seen as being seen out of touch with the needs of those affected by a crisis.

The relationship between digital technology use patterns and long-term information processing styles may be more complex and potentially bi-directional. For example, individuals with weaker executive control and higher levels of impulsivity and sensation seeking also multitask more (Sanbonmatsu, Strayer, Medeiros-Ward, \& Watson, 2013). People who tend to 
think more intuitively rather than analytically also tend to rely on their smartphones more and offload higher order cognition onto these tools (Barr, Pennycook, Stolz and Fugelsang, 2015).

In the context of emergency management, the misalignment between the unique environmental demands of the digital environment, managers' personal abilities, and characteristics of their organizational environments results in overload, stress, and decisionmaking impediments (Misra, Roberts, \& Rhodes, 2018; Misra, Roberts, \& Rhodes, 2020). While digital technologies may enable emergency managers to standardize information across arenas, provide a common operating picture for team members and first responders, and provide means of sharing information, the design of technology, its use in the emergency managerial context, and the personal and organizational attributes are critical moderating factors. For example, Jaeger, et. al. (2007) examined the information exchange gap between first responders and the public, with first responders using their own top-down networks and the community using neighborhood watch programs, texts, and social media. This created differences between the types of information being collected and used. The authors recommend a Community Response Grid placed in highly public areas, like libraries, to better enable emergency managers to collect information and share it more easily with the community. Personal and organizational attributes may include heuristics and shortcuts such as beliefs about a situation, which emergency and crisis managers use to make faster decisions during times of unpredictability (Houghton, 2020).

Another challenge faced by emergency and crisis managers in the digital environment is that technological solutions may not be designed for the needs of the people intended to use them. For example, cost and accessibility are significant barriers to using social media networks to provide critical information to people with disabilities during emergencies (Bricout, et. al., 2010). The elderly, defined as people over 65 years of age, lag behind younger demographic 
groups when it comes to internet use and face similar accessibility challenges. Only $66 \%$ of people over the age of 65 use the internet, versus $87 \%$ of people 50 to 64 years old and $97 \%$ of people 49 years of age and younger (Pew, 2018). Elderly individuals with disabilities are even less likely to use the internet, with only $49 \%$ reporting internet use (Pew, 2014). Physical changes in elderly people may also be barriers to accessing social media networks. Individuals over the age of 65 are more likely to have difficulty with vision or hearing, with $37.3 \%$ of elderly people reporting challenges in hearing and vision, and 36.2\% reporting mobility issues (Stough and Mayhorn, 2013). Therefore, although digital technologies may provide significant benefits for emergency communications, there can be a misalignment between their design and intended users (Integrating Access and Functional Needs in Community Planning for Natural Hazards).

\section{Reducing Cognitive Biases: Tools for Emergency and Crisis Managers Subject to Digital Distraction}

A number of strategies could mitigate the negative effects of digital technology on emergency and crisis managers. Fields such as aviation and medicine have addressed the potential for information overload and distraction by adopting the use of checklists, simulations, and exercises (Clay-Williams and Colligan 2015; Gawande 2009). Checklists help experts slow down and pay attention, and can ensure that vital steps in a routine are not overlooked. When pilots overlook their checklists, things can go wrong, as in the famous example of the Air Florida crash in 1982 in Washington, DC (Cocklin and Hammhire 2004; Gawande 2009). The pilots failed to use procedures designed to mitigate the effects of the weather, including a failure to turn on ice protection systems. Checklists could have forced the pilots to slow down and take the recommended precautions before taking off. Checklists are now standard in fields such as 
medicine or construction where work is complex and mistakes can be costly (Gawande 2009). They have proven their utility in many fields, but when coupled with an inflexible procedure they can hamper emergency and crisis management. After Hurricane Katrina, the state of Louisiana and the federal government were criticized for being too slow to provide relief supplies because of a complicated chain of procedures in which the federal government intervenes at the request of a governor, and then follows steps to distribute aid to those who need it most while preventing waste, fraud, and abuse (Boin, t'Hart, McConnell, Preston 2010; Derthick, 2007). Meanwhile, Wal-Mart played a larger role than anticipated by stocking stores with hurricane-preparation supplies in advance of the storm and restocking immediately after the storm passed (Rosegrant and Leonard, 2007). Though some commentators have criticized checklists for being stultifying (e.g. Behesti, 2019), Wal-Mart probably used checklists to identify what should be in stock. The government's problem was not that it used too many checklists, but that the constitutional separation of federal and state governments combined with protections against waste, fraud, and abuse and the need to direct resources to those who need it most added layers of complexity that slowed disaster response (Birkland and Waterman 2018; Roberts 2013, 127-145).

Another way to mitigate effects of overload and the digital environment is to conduct exercises and simulations of situations in which failure can be costly (Bartley, Stella, Walsh 2006; Kleiboer 1997). Emergency and crisis managers routinely rehearse emergency situations; exercises could become an even more important part of training in a digital age. Sometimes exercises are shortened or eliminated because of budget constraints, but they are particularly important for managers who might be susceptible to biases in the digital environment. 
The ill effects of the digital age may require specific efforts tailored to mitigate each effect. For example, the propensity for tunnel vision and quick, intuitive reactions may need to be slowed down in situations where more long term and deliberative thinking is called for. The planning and preparation phase of emergency and crisis management, as well as long-term recovery, can offer longer potential times for decision-making and the need for weighing tradeoffs and evaluating alternative paths. Decision processes can be more formal or informal, but some structure can help make a space for deliberative thinking. Environmental resource management has long used structured decision techniques, and some of these could be applied to crisis management (Gregory et al., 2012).

\section{The Use of Digital Tools for Reducing Digital Overload and Distraction}

Some digital tools hold out the possibility for reducing the problems of digital overload and distraction. At the inter- and intra-organizational level, logistical tools aim to improve coordination and to use the proliferation of information during disasters--paradoxically too much during a disaster, but also too spotty and unreliable--to manage the flow of goods and services. Tools for "intelligent decision-making" predict future consequences of a disaster in order to forecast need, and assess obstacles to the crucial "last mile" problem in delivering disaster aid (Vitoriano et al. 2014). It is often easier to deliver aid over a long distance to a region than it is to deliver aid a short distance to those in need given the breakdown of local transportation and communication networks in the wake of disaster. During Hurricane Maria in 2017, Puerto Rico suffered from the last mile problem when aid was delivered to the restored seaport and airport in San Juan but took longer to reach rural areas. Developers created tools to help the problem. An ArcGIS app with preloaded maps allowed responders to take a handheld device into devastated 
rural areas and note where people needed help and what they needed, all without internet or cell service (ESRI 2018; Supporting Natural Hazards Management With Geospatial Technologies)).

At the organizational level, decision support systems attempt to aid judgment under the time pressure of an emergency and during the challenge of coordinating across organizational silos or organizations themselves (Walle and Turoff, 2008). These support systems may have organizational components, but most often they are digital tools such as dashboards, cloud-based data storage, text message systems, or social media platforms. ICTs can play a role in how emergency managers perceive their environment and the decisions that are available to them.

Johnson, et. al. (2011) define situational awareness as the ability to perceive a crisis in its current form and to consider potential risks, as well as mitigation strategies and response to threats in the future. There are two primary obstacles to situational awareness: the increasing flow of information and the varying abilities and skills of employees assigned to an Emergency Operations Center, tasked with managing a crisis. The authors find that a Situational Awareness Model (SAM) with a web interface could automate information gathering and analysis, presenting data and simulations to emergency managers so that they can increase situational awareness and then make better decisions regardless of their experience or ability level. At a practical level, the SAM would distill information into relevant categories, combine data sources, and present various visualizations relevant to a decision at hand. For example, it could combine reports from river gauges to give a picture of the relative risk of a flood.

At a theoretical level, the SAM model would appear to address the misalignment between environmental demands and managerial capabilities by using ICTs to conduct analysis that can augment the abilities of an emergency manager. Other literature, such as Perry, et. al.'s (2012) examination of reduced processing in decision support systems, indicates that incident 
commanders with more experience made more accurate decisions than incident commanders with less experience, and that ICTs may help less-experienced incident commanders overcome this gap to raise their abilities to that of more experienced incident commanders.

Through interviews with German firefighters and ambulance services and from observation, Artinger et. al. (2012) developed 11 requirements that devices like tablets should have in their user interfaces to minimize distraction and help responders to concentrate during a mass casualty incident, such as the ability to guide responders through basic tasks that are critical to situational awareness but can be missed due to stress, cognitive load, and multitasking. For emergency managers who communicate with the public, developing "mental models" to provide individuals with basic information may help those individuals alleviate their stress and facilitate decisionmaking (Bricout 2010, Glik 2007).

The proliferation of social media information has made it difficult to assess the veracity of the information. Most solutions to verifying social media information focus on large-scale analytic packages used by a central authority such as state or local emergency management office, but there is a need for more tools that can help citizens or field workers verify information and assess conditions (Conrado et al 2016). For example, the FEMA offered a rumor control F.A.Q. on its website dedicated to quelling rumors and providing correct information about COVID-19. However, local emergency managers, public health officials, and community leaders faced rumors specific to their community and needed a way to verify new information and communicate trusted assessments to residents. For example, in March 2020, one Michigan nursing home was the target of a false rumor that the home had been importing COVID-19 patients. The nursing home was left to combat the rumor on its own through Facebook and in the local media because there was no public organization devoted to dispelling rumors (Hershovitz 
and Tam, 2020). Most solutions to verifying social media information focus on large-scale analytic packages used by a central authority such as state or local emergency management office, but there is a need for more tools that can help citizens or field workers verify information and assess conditions (Corado et al., 2016).

Some ICTs and organizational remedies are designed to help managers cope -- emergency management has always relied on organizational tools, but increasingly digital tools are used to manage the flow of information. At its core, emergency management requires coordination more than hierarchical control (Comfort 2007). Emergency managers at all levels of government operate in relatively small organizations, and during a disaster they work with government agencies, nonprofits, and the public to respond to a major event. Emergency managers work with these same groups before a disaster to shore up defenses, move people and things out of harm's way, and plan for response. Emergency managers control very few assets and people, so purely hierarchical forms of management are insufficient. Formal coordination mechanisms have long guided emergency managers. At the state level, Emergency Management Assistance Compacts (EMACs) formalize agreements among and between states to share resources and provide mutual aid when one is affected by disaster. (Kapucu and Garayev, 2011). EMACs also provide for reimbursement when one state's people and resources come to the aid of another. The possibility exists for combining formal agreements such as EMACs with real time information about logistics availability and need.

\section{The Future of Research on Emergency and Crisis Management in the Distracted Digital} Age

This essay discussed how digital technologies have fundamentally altered the structure and functioning of emergency and crisis managerial environments and outlined some of the 
negative cognitive implications of these transformative changes. This essay also

proposed a number of organizational and technological interventions that have the potential to reduce digital overload and stress and improve managerial thinking and decision-making.

The paradox of crisis management in the digital environment is that information overload is combined with the manager's deficit of reliable information and the inability to prioritize information in the moment of the crisis. Effective crisis and emergency managerial decisionmaking in the digital environment will depend on the congruence between managers' personal abilities and their organizational, technological, and socio-political environments. Future research on emergency and crisis managerial decision-making should: (1) Conceptualize the environment of emergency and crisis management to include physical-environmental, virtual, intra-organizational, inter-organizational, as well as broader socio-political factors; (2) Investigate the synergistic, short-term as well as longer-term impacts of organizational and technological interventions on specific types of crisis managerial decision-making. Intraorganizational interventions include the redesign task routines for independence or interdependence, experimenting with routines that differentiate between deep work and shallow work that allow the freeing up of mental resources for thoughtful decision-making, increasing staffing levels, and hiring individuals for breadth, diversity, and complementarity of backgrounds and experiences; and finally (3) Work across disciplinary boundaries to design training interventions to hone managers' critical thinking skills and encourage effective boundary regulation mechanisms to manage and counter digital overload. 


\section{Bibliography}

Barr, N., Pennycook, G., Stolz, J. A., \& Fugelsang, J. A. (2015). The brain in your pocket: Evidence that Smartphones are used to supplant thinking. Computers in Human Behavior, 48, 473-480.

Birkland, T., \& Waterman, S. (2008). Is federalism the reason for policy failure in Hurricane Katrina? Publius: The Journal of Federalism, 38(4), 692-714.

Boin, A. Stern, E. and Sundelius, B. (2016). The politics of crisis management: Public leadership under pressure. Cambridge University Press.

Boin, A., T'Hart, P., McConnell, A., \& Preston, T. (2010). Leadership style, crisis response and blame management: The case of Hurricane Katrina. Public Administration, 88(3), 706-723

Boswell, W. R., Olson-Buchanan, J. B., Butts, M. M., \& Becker, W. J. (2016). Managing "after hours" electronic work communication. Organizational Dynamics, 45(4), 291-297.

Brumby, D. P., Cox, A. L., Back, J., \& Gould, S. J. (2013). Recovering from an interruption: Investigating speed-accuracy trade-offs in task resumption behavior. Journal of Experimental Psychology: Applied, 19(2), 95-107.

Butts, M. M., Becker, W. J., \& Boswell, W. R. (2015). Hot buttons and time sinks: The effects of electronic communication during nonwork time on emotions and work-nonwork conflict. Academy of Management Journal, 58(3), 763-788.

Cades, D. M., Davis, D. A. B., Trafton, J. G., \& Monk, C. A. (2007, October). Does the difficulty of an interruption affect our ability to resume?. In Proceedings of the human factors and ergonomics society annual meeting (Vol. 51, No. 4, pp. 234-238). Sage CA: Los Angeles, CA: SAGE Publications.

Cain, M. S., \& Mitroff, S. R. (2011). Distractor filtering in media multitaskers. Perception, 40, 1183-1192. doi:10.1068/p7017

Csikszentmihalyi, M., Abuhamdeh, S., \& Nakamura, J. (2014). Flow. In Flow and the foundations of positive psychology (pp. 227-238). Springer, Dordrecht.

Clay-Williams, R., \& Colligan, L. (2015). Back to basics: checklists in aviation and healthcare. BMJ Qual Saf, 24(7), 428-431. 
Cocklin, J. T., \& Hammhire, H. N. (2004). Swissair 111 human factors: Checklists and cockpit communication. Journal of Air Transportation, 9(3), 19.

Collier, S. J., \& Lakoff, A. (2015). Vital systems security: Reflexive biopolitics and the government of emergency. Theory, Culture \& Society, 32(2), 19-51.

Collier, S. J., \& Lakoff, A. (2008). Distributed preparedness: the spatial logic of domestic security in the United States. Environment and planning D: Society and space, 26(1), 7-28.

Conrado, S. P., Neville, K., Woodworth, S., \& O’Riordan, S. (2016). Managing social media uncertainty to support the decision making process during emergencies. Journal of Decision Systems, 25(sup1), 171-181.

Derthick, M. (2007). Where federalism didn't fail. Public Administration Review, 67, 36-47.

DeStefano, D., \& LeFevre, J. A. (2007). Cognitive load in hypertext reading: A review. Computers in human behavior, 23(3), 1616-1641.

DiFonzo, N. (2013). Rumour research can douse digital wildfires. Nature, 493(7431), 135-135.

Edmunds, A., \& Morris, A. (2000). The problem of information overload in business organisations: a review of the literature. International Journal of Information Management, 20(1), 17-28. doi:https://doi.org/10.1016/S0268-4012(99)00051-1

Eppler, M., \& Mengis, J. (2004). The concept of information overload: A review of literature from organization science, accounting, marketing, MIS, and related disciplines. Information Society, 20(5), 325-344. doi:10. 1080/01972240490507974

ESRI. (2018). "ArcGIS Disconnected Apps Transform Hurricane Response in Puerto Rico," Redlands, CA, Fall. Available at: https://www.esri.com/about/newsroom/arcnews/arcgisdisconnected-apps-transform-hurricane-response-in-puerto-rico/

Farhoomand, A. F., and D. H. Drury. "Managerial Knowledge Overload." Communications of the ACM 45, no. 10 (2002): 127-131.

Foerde, K., Knowlton, B. J., \& Poldrack, R. A. (2006). Modulation of competing memory systems by distraction. proceedings of the National Academy of Sciences, 103(31), 11778-11783.

Frein, S. T., Jones, S. L., \& Gerow, J. E. (2013). When it comes to Facebook there may be more to bad memory than just multitasking. Computers in Human Behavior, 29(6), 2179-2182.

Gawande, A. 2009. The Checklist Manifesto. New York: Henry Holt. 
Gergen, K. (2010). Mobile Communication and the New Insularity. Qwerty-Open and Interdisciplinary Journal of Technology, Culture and Education, 5(1), 14-28.

González, V. M., \& Mark, G. (2004, April). " Constant, constant, multi-tasking craziness" managing multiple working spheres. In Proceedings of the SIGCHI conference on Human factors in computing systems (pp. 113-120).

Greenfield, P. M. (2009). Linking social change and developmental change: shifting pathways of human development. Developmental psychology, 45(2), 401.

Gregory, R., Failing, L., Harstone, M., Long, G., McDaniels, T., \& Ohlson, D.

(2012). Structured decision making: a practical guide to environmental management choices. John Wiley \& Sons.

Hadar, A. A., Eliraz, D., Lazarovits, A., Alyagon, U., \& Zangen, A. (2015). Using longitudinal exposure to causally link smartphone usage to changes in behavior, cognition and right prefrontal neural activity. Brain Stimulation: Basic, Translational, and Clinical Research in Neuromodulation, 8(2), 318.

Hayden, T. (2020).Office of Emergency management to be folded into fire dept? Santa Barbara Independent. Jan. 24. Available at: https://www.independent.com/2020/01/24/office-ofemergency-management-to-be-folded-into-fire-dept/

Hembrooke, H., \& Gay, G. (2003). The laptop and the lecture: The effects of multitasking in learning environments. Journal of computing in higher education, 15(1), 46-64.

Hershovitz, X. and M. Tamm. (2020). Northern Michigan Nursing Home Target of False Coronavirus Rumor. 9 and 10 News, Michigan. Available at: https://www.9and10news.com/2020/03/25/northern-michigan-nursing-home-center-of-falsesocial-media-coronavirus-rumors/

Houghton, D. P. (2020). Multiple Perspectives and Comparative Case Studies of Crisis Decision Making. In Oxford Research Encyclopedia of Politics.

Hwang, M. I., \& Lin, J. W. (1999). Information dimension, information overload and decision quality. Journal of information science, 25(3), 213-218.

Ingraham, P, W. (2009). Leadership in the unglued organization. Public sector leadership: international challenges and perspectives: 214.

Jung, C. S. (2013). Organizational goal ambiguity and job satisfaction in the public sector. Journal of Public Administration Research and Theory, 24(4), 955-981. 
KC, D. (2014). Does multitasking improve performance? Evidence from the emergency department. Manufacturing \& Service Operations Management, 16(2), 168-183.

Kleiboer, M. (1997). "Simulation methodology for crisis management support." Journal of Contingencies and Crisis Management 5 (4): 198-206.

Leiva, L., Böhmer, M., Gehring, S., \& Krüger, A. (2012, September). Back to the app: the costs of mobile application interruptions. In Proceedings of the 14th international conference on Human-computer interaction with mobile devices and services (pp. 291-294).

Levy, E. C., Rafaeli, S., \& Ariel, Y. (2016). The effect of online interruptions on the quality of cognitive performance. Telematics and Informatics, 33(4), 1014-1021.

LexisNexis (2010). LexisNexis 2010 International Workplace Productivity Survey. Available online at: http://www.multivu.com/players/English/46619-LexisNexis-International-WorkplaceProductivity-Survey/

Lin, L. (2009). Breadth-biased versus focused cognitive control in media multitasking behaviors. Proceedings of the National Academy of Sciences of the United States of America, 106(37), 15521-15522. doi:10.1073/pnas.0908642106

Lu, X., \& Han, Z. (2019). Emergency management in China: towards a comprehensive model?. Journal of Risk Research, 22(11), 1425-1442.

Mark, G., Voida, S., \& Cardello, A. (2012, May). " A pace not dictated by electrons" an empirical study of work without email. In Proceedings of the SIGCHI conference on human factors in computing systems (pp. 555-564).

Mark, G., Gonzalez, V. M., \& Harris, J. (2005, April). No task left behind? Examining the nature of fragmented work. In Proceedings of the SIGCHI conference on Human factors in computing systems (pp. 321-330).

Mark, G., Gudith, D., \& Klocke, U. (2008, April). The cost of interrupted work: more speed and stress. In Proceedings of the SIGCHI conference on Human Factors in Computing Systems (pp. 107-110).

Miall, D. S., \& Dobson, T. (2001). Reading hypertext and the experience of literature. Journal of digital information, 2(1).

Milner, G. (2016). Pinpoint: how GPS is changing technology, culture, and our minds. WW Norton \& Company. 
Misra, S., Cheng, L., Genevie, J., \& Yuan, M. (2016). The iPhone effect: the quality of in-person social interactions in the presence of mobile devices. Environment and Behavior, 48(2), 275-298.

Misra, S., Roberts, P., \& Rhodes, M. (2020). The Ecology of Emergency Management Work in the Digital Age. Perspectives on Public Management and Governance.

Misra, S., Roberts, P. and M. Rhodes. 2018. Information overload, stress, and emergency management thinking. Paper presented at the Association for Public Policy Analysis and Management Conference, Washington, DC, November 10.

Misra, S., \& Stokols, D. (2012). Psychological and health outcomes of perceived information overload. Environment and behavior, 44(6), 737-759.

Monk, C. A. (2004, September). The effect of frequent versus infrequent interruptions on primary task resumption. In Proceedings of the Human Factors and Ergonomics Society Annual Meeting (Vol. 48, No. 3, pp. 295-299). Sage CA: Los Angeles, CA: SAGE Publications.

Moore, L. K. (2010). The emergency alert system (EAS) and all-hazard warnings. Washington, DC: Congressional Research Service RL32527.

Mosier, K. L., Skitka, L. J., Burdick, M. D., \& Heers, S. T. (1996, October). Automation bias, accountability, and verification behaviors. In Proceedings of the Human Factors and Ergonomics Society Annual Meeting (Vol. 40, No. 4, pp. 204-208). Sage CA: Los Angeles, CA: SAGE Publications.

National Academies of Sciences, Engineering, and Medicine. (2012). Education for Life and Work: Transferable Knowledge and Skills in the 21st Century (National Academies Press, Washington DC, 2012); https://doi.org/10.17226/13398

Niederhauser, D. S., Reynolds, R. E., Salmen, D. J., \& Skolmoski, P. (2000). The influence of cognitive load on learning from hypertext. Journal of educational computing research, 23(3), 237-255.

Ophir, E., Nass, C., Wagner, A. D., \& Posner, M. I. (2009). Cognitive control in media multitaskers. Proceedings of the National Academy of Sciences of the United States of America, 106(37), 15583-15587.

Parasuraman, R., \& Manzey, D. H. (2010). Complacency and bias in human use of automation: An attentional integration. Human factors, 52(3), 381-410. 
Pea, R., Nass, C., Meheula, L., Rance, M., Kumar, A., Bamford, H., Zhou, M. (2012). Media use, face-to-face communication, media multitasking, and social well-being among 8- to 12year-old girls. Developmental Psychology, 48(2), 327-336. doi:10.1037/a0027030

Peters, T. J. (1992). Liberation management. AA Knopf.

Poldrack, R. A., \& Foerde, K. (2008). Category learning and the memory systems debate. Neuroscience \& Biobehavioral Reviews, 32(2), 197-205.

Reid, M. F., Riemenschneider, C. K., Allen, M. W., \& Armstrong, D. J. (2008). Information technology employees in state government: A study of affective organizational commitment, job involvement, and job satisfaction. The American Review of Public Administration, 38(1), 41-61.

Renaud, K., Ramsay, J., \& Hair, M. (2006). " You've got e-mail!"... shall I deal with it now? Electronic mail from the recipient's perspective. International Journal of Human-Computer Interaction, 21(3), 313-332.

Risko, E. F., \& Gilbert, S. J. (2016). Cognitive offloading. Trends in cognitive sciences, 20(9), 676-688.

Roberts, P. S. (2013). Disasters and the American state: How politicians, bureaucrats, and the public prepare for the unexpected. Cambridge University Press.

Rockwell, S. C., \& Singleton, L. A. (2007). The effect of the modality of presentation of streaming multimedia on information acquisition. Media Psychology, 9(1), 179-191. doi:10.1080/15213260701279689

Sagun, A., Bouchlaghem, D., and Anumba, C.J. (2009). A scenario-based study on information flow and collaboration patterns in disaster management. Disasters. 33(2), 214-238.

Sanbonmatsu, D. M., Strayer, D. L., Medeiros-Ward, N., \& Watson, J. M. (2013). Who multitasks and why? Multi-tasking ability, perceived multi-tasking ability, impulsivity, and sensation seeking. PloS one, 8(1), e54402.

Smith, William R., Keri K. Stephens, B. R. Robertson, Jing Li, and Dhiraj Murthy. (2018) "Social media in citizen-led disaster response: Rescuer roles, coordination challenges, and untapped potential." In Proceedings of the... International ISCRAM Conference. 
Speier, C., Valacich, J. S., \& Vessey, I. (1999). The influence of task interruption on individual decision making: An information overload perspective. Decision Sciences, 30(2), 337-360.

Starbird, K., Maddock, J., Orand, M., Achterman, P., \& Mason, R. M. (2014). Rumors, false flags, and digital vigilantes: Misinformation on twitter after the 2013 boston marathon bombing. IConference 2014 Proceedings. Do rumors proceed like digital wifldires?

Stern, E. K. 2017. Unpacking and exploring the relationship between crisis management and social media in the era of "smart devices." Homeland Security Affairs $\mathbf{1 3}$

4).https://www.hsaj.org/articles/13986.

Stokols, D., Misra, S., Runnerstrom, M. G., \& Hipp, J. A. (2009). Psychology in an age of ecological crisis: From personal angst to collective action. American Psychologist, 64(3), 181.

Stone, J. T., Waldman, S., \& Yumagulova, L. (2019). Filling the gaps: the potential and limitations of emergent, ICT-enabled organisation in disaster-a case study of the Cajun Army. Environmental Hazards, 1-15.

Stothart, C., Mitchum, A., \& Yehnert, C. (2015). The attentional cost of receiving a cell phone notification. Journal of experimental psychology: human perception and performance, 41(4), 893.

Sutton, J., L. Palen, and I. Shklovski (2008). Backchannels on the Front Lines: Emergent Uses of Social Media in the 2007 Southern California Wildfires. Proceedings of the Fifth International ISCRAM Conference, Washington, DC. pp. 624-631.

Takayasu, M., Sato, K., Sano, Y., Yamada, K., Miura, W., \& Takayasu, H. (2015). Rumor diffusion and convergence during the 3.11 earthquake: a Twitter case study. PLoS one, 10(4).

Turkle, S. (2012). Alone Together: Why We Expect More from Technology and Less from Each Other (2011). New York: Basic.

Torres, L., Pina, V., \& Acerete, B. (2005). E-government developments on delivering public services among EU cities. Government Information Quarterly, 22(2), 217-238.

Uncapher, M. R., Thieu, M. K., \& Wagner, A. D. (2016). Media multitasking and memory: Differences in working memory and long-term memory. Psychonomic bulletin \& review, 23(2), 483-490.

Van de Walle, B., \& Turoff, M. (2008). Decision support for emergency situations. In Handbook on decision support systems 2 (pp. 39-63). Springer, Berlin, Heidelberg. 
Vitoriano, B., Rodríguez, J. T., Tirado, G., Martín-Campo, F. J., Ortuño, M. T., \& Montero, J. (2015). Intelligent decision-making models for disaster management. Human and Ecological Risk Assessment: An International Journal, 21(5), 1341-1360.

Weber, E. P., \& Khademian, A. M. (2008). Wicked problems, knowledge challenges, and collaborative capacity builders in network settings. Public Administration Review, 68(2), 334349.

Wilmer, H. H., Sherman, L. E., \& Chein, J. M. (2017). Smartphones and cognition: A review of research exploring the links between mobile technology habits and cognitive functioning. Frontiers in psychology, 8, 605.

Wooten, L. P., \& James, E. H. (2008). Linking crisis management and leadership competencies: The role of human resource development. Advances in developing human resources, 10(3), 352379.

Xiao, Y., Huang, Q., \& Wu, K. (2015). Understanding social media data for disaster management. Natural hazards, 79(3), 1663-1679. 